\title{
PELATIHAN PEMASARAN PRODUK BERBASIS DIGITAL DI KELURAHAN GEBANG, MASARAN, SRAGEN
}

\author{
Septiana Novita Dewi ${ }^{1}$, Aris Tri Haryanto ${ }^{2}$, Ambar Wariati ${ }^{3}$ \\ Sekolah Tinggi llmu Ekonomi Adi Unggul Bhirawa Surakarta \\ Septianadewi25@vahoo.co.id ${ }^{1}$, Arisharvanto26@vahoo.co.id ${ }^{2}$, ambarwariati@vahoo.co.id ${ }^{3}$
}

\begin{tabular}{ll}
\hline Info Artikel & Abstract \\
\cline { 2 - 3 } Masuk: & Pengabdian ini merupakan pengabdian lanjutan dari proses \\
Revisi: & pengabdian sebelumnyam bahwa di Kelurahan Desa Gebang \\
Diterima: & memiliki potensi untuk ditingkatkan UMKM makanan ringan. \\
Terbit: & Dengan adanya peningkatan UMKM di Kelurahan Gebang, akan \\
Keywords: & dapat meningkatkan kesejahteraan masyarakat di lingkungannya. \\
UMKM, Digital Marketing, & Akan tetapi dalam pemasaran produk UMKM masyarakat di \\
Kelurahan Gebang & Kelurahan Gebang belum dimbangi dengan adanya pemanfaatan \\
& alat tekhnologi, sehingga proses pemasaran belum optimal. Hal \\
P-ISSN: 2598-2273 & ini disebabkan karena rata-rata pelaku UMKM memiliki usia yang \\
E-ISSN: 2598-2281 & tidak muda lagi, sehingga perlu pendampingan yang lebih ekstra. \\
DOI : 10.33061 & Pada saat era milineal ini, semua disajikan secara praktis dan \\
& efisien yaitu dengan memanfaatkan tekhnologi informasi. Seperti \\
& pemasaran melalui akun facebook, Instagram, website, twitter \\
& dan lain-lain. Hal ini bertujuan bahwa dengan menggunakan \\
& tekhnologi informasi, semua informasi produk dapat \\
& tersampaikan secara luas, baik tingkat nasional maupun \\
& internasional. Permasalahan yang utama ketika UMKM tidak \\
& memanfaatkan tekhnologi informasi dengan baik adalah mereka \\
& hanya bisa menjual produknya secara lokal dan jenis-jenis \\
& produk yang dijual tidak tersampaikan secara luas. Dalam \\
& mensiatasi kompetensi bisnis di era digital diharapkan seluruh \\
& UMKM memahami dan menggunakan digital marketing dengan \\
& baik, agar mereka mampu bersaing dengan baik hingga mencapai \\
keunggulan k;ompetitif lebih maksimal. Materi yang diberikan \\
kepada UMKM di Kelurahan Desa Gebang adalah tujuh konsep \\
pemasran ampuh dengan metode digital, diantaranya adalah \\
Search Engine Optimization (SEO), Search Engine Marketing \\
(SEM), Pembuatan Konten, Mobile Marketing, Email Marketing, \\
Affiliate Marketing, Pemasaran Media Sosial.
\end{tabular}

\section{PENDAHULUAN}

Salah satu desa di Kabupaten Sragen yang memiliki potensi UMKM adalah Kelurahan Gebang Kecamatan Masaran. Kecamatan Masaran adalah sebuah kecamatan sebelah barat berbatasan dengan Kecamatan Plupuh, di sebelah selatan berbatasan dengan Kabupaten Karanganyar, di sebelah timur berbatasan dengan Kecamatan Kedawung dan di sebelah utara berbatasan dengan Kecamatan Sidoharjo. Kecamatan Masaran sekaligus sebagai pintu gerbang masuk ibu kota Kabupaten Sragen dari arah barat. Kecamatan Masaran terletak di sebelah barat daya ibu kota Kabupaten Sragen dan hanya berjarak $13 \mathrm{Km}$. Kecamatan Masaran terdiri atas tiga belas desa. Rata-rata penduduknya mempunyai mata pencaharian sebagai pegawai swasta, pedagang, petani, PNS, purnawirawan dan berbagai 
profesi pengusaha kecil yang beragam mulai dari pengusaha pengusaha tahu, pengusaha jajanan sampai kerajinan kain bekas. Mata pencaharian sebagai pengusaha kecil dari masyarakat desa ini sangat memungkinkan karena letak lokasi yang sangat strategis yaitu dekat dengan pasar tradisional.

Kedaaan geografis di Kabupaten Sragen memiliki keadaan alam dengan relief yang beraneka ragam. Kabupaten sragen merupakan daerah pegunungan kapur yang membentang dari timur ke barat yang terletak di sebelah utara bengawan Solo. Kabupaten sragen yang terletak di Provinsi Jawa Tengah, Indonesia. Memiliki 20 kecamatan, 12 kelurahan, dan 196 desa. Pada tahun 2017, jumlah penduduknya mencapai 981.416 jiwa dengan luas wilayah $941,54 \mathrm{~km}^{2}$ dan sebaran penduduk $1.042 \mathrm{jiwa} / \mathrm{km}$. peta administrasi Kabupaten Sragen adalah sebagai berikut:

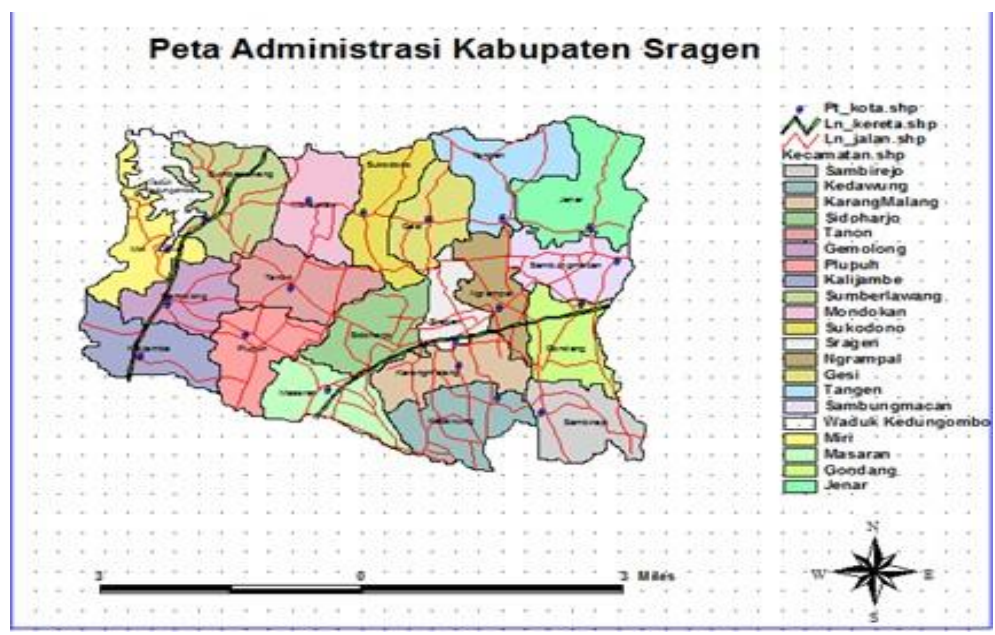

Sumber Peta Kab. Sragen: www.google.kab.sragen.co.id (Diakses pada tanggal 18 April 2019)

Dengan banyaknya UMKM di Kelurahan Gebang perlu di dorong agar dapat memanfaatkan pemasaran secara digital di era milineal saat ini. Bebrapa manfaat yang diperoleh ketika menggunakan pemasaran secara digital diantaranya adalah mampu menguhubungkan UMKM dengan konsumen secara luas dengan jaringan internet, menghasilkan penjualan lebih tinggi karena pemasaran dilakukan secara luas, dapat menghemat proses penjualan, menghasilkan pendapatan yang lebih besar, mempertahankan pelanggan dan memberikan kepuasan layanan terhadap konsumen.

Selain itu pemasaran digital dapat memanfaatkan mobile smartphone yang dimiliki yang mudah diakses kapanpun diwaktu luang. Dan dengan menggunakan digital marketing akan membuat UMKM bersaing dengan perusahaan besar. Karena dengan memanfaatkan media sosial internet siapapun bisa mengakses dan melihat produk-produk UMKM yang ditanyangkan untuk umum. Alasan lain kenapa UMKM perlu memanfaatkan digital marketing adalah agar UMKM dapat menyambut era milineal ini dengan cepat dan mampu mengikuti perkembangan pemasaran produk dengan baik. 
Hasil evaluasi yang disampaikan oleh Gartner bahwa pada tahun 2020 diperkirakan adanya 26 miliar gadget, smartphone, tablet, jam tangan, kacamata, sepatu dan peralatan lainnya yang akan saling terhubung dalam ekosistem online secara global yang akan membentuk era Internet of Things.

Fakta Infografis Hasil Digital Marketing bahwa tingkat kepercayaan terhadap iklan online atau dengan kata lain hasil dari pemasaran digital di kawasan Asia Tenggara: Search engine : $57 \%$, Sosial media : $53 \%$, Video online : $52 \%$, Online banner : $47 \%$. Saat ini, iklan-iklan yang tersedia di search engine meraih kredibiltas tertinggi. Hampir 6 dari 10 orang (57\%) konsumen mengindikasikan percaya pada saluran ini. Thailand meraih skor kepercayaan tertinggi yakni $63 \%$, Indonesia $61 \%$, Filipina 56\% dan Vietnam 55\%. Sementara itu, kredibilitas iklan di jejaring sosial dan iklan video online mendapatkan skor kepercayaan masing-masing $53 \%$ dan $52 \%$. Kepercayaan iklan video meningkat di empat negara Asia Tenggara, tertinggi di Filipina dan Thailand dengan skor 56\%, Vietnam dan Indonesia dengan angka 52\%, Singapura 47\% dan Malaysia 41\%. (Sumber: Business2Community: Top 10 Benefits of Digital Marketing for Small Business (Infographic)

Berdasarkan data di atas, diketahui bahwa banyak masyarakat yang menggunakan media sosial di setiap harinya, hal ini sebesar $53 \%$ masyarakat mengakses media social dalam aktivitas-aktivitas setiap hari. Dengan adanya data tersebut UMKM dapat mengambil strategi yang tepat dengan cara memahami dan menggunakan digital marketing dalam pemasaran produknya

\section{RUMUSAN MASALAH}

Permasalahan utama yang dihadapi oleh UMKM di Kelurahan Gebang Kecamatan Masaran Kabupaten Sragen adalah bagaimana caranya dapat menggunakan digital marketing dengan memanfaatkan media social dalam memasarkan produk-produk yang mereka hasilkan. Dengan adanya permasalahan pada UMKM tersebut, maka gagasan solusi berdasarkan teori dan hasil penelitian yang ada, maka prioritas utama yang perlu untuk dilakukan adalah sebagai berikut :

1. Memberikan gambaran apa yang dimasud dengan media sosial.

2. Memberikan penjelasan tentang manfaat pemasaran produk menggunakan media sosial.

3. Mendampingi UMKM untuk mendaftar di media sosial.

4. Memberikan penjelasan serta mendampingi cara mengakses dan menampilkan produk-produk UMKM yang telah dihasilkan.

\section{METODE PENELITIAN}

Sasaran dalam kegiatan ini adalah UMKM di Kelurahan Gebang Kecamatan Masaran Kabupaten Sragen, yang telah mengikuti kegiatan pengabdian, melalui praktik dan penyampaian materi oleh Tim Pengabdian kepada masyarakat. Kegiatan Pengabdian Kepada Masyarakat ini dilakukan di Kelurahan Gebang dengan cara meemberikan sosialisasi kepada pelaku UMKM di Kelurahan Gebang Kecamatan Masaran Kabupaten Sragen.

Metode penyelesaian untuk mengatasi permasalah diatas yaitu dengan memberikan pengetahuan, pemahaman dan ketrampilan kepada mitra yaitu UMKM 
Kelurahan Gebang, Masarag, Sragen berupa pengenalan teknologi informasi. Dengan mengenalkan kepada mereka digital marketing dengan mendafkarkan UMKM agar memiliki akun facebook, Instagram maupun website untuk dapat digunakan sebagai media pemasaran.

Tahapan yang ingin dicapai dari proses pengabdian masyarakat ini adalah sebagai berikut:

\section{Menyusun target dan strategi}

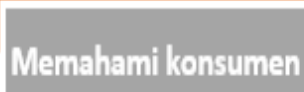

Memahami brand yang diusung

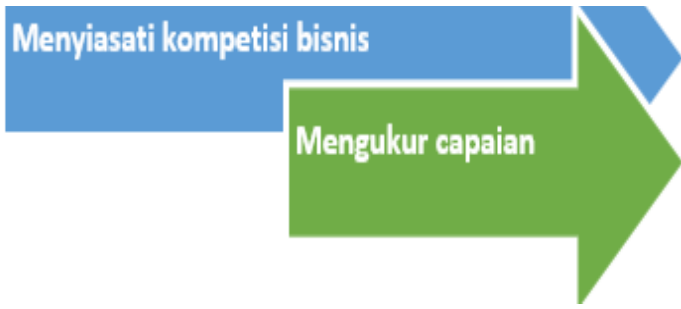

\section{HASIL DAN PEMBAHASAN}

\section{Menyusun Target Strategi}

Jika melihat karakteristik konsumen modern yang ada saat ini, tidak diragukan lagi bahwa pendekatan strategi pemasaran digital menjadi sesuatu yang sangat layak dipertimbangkan, terlebih untuk startup digital. Strategi pemasaran digital dapat didefinisikan sebagai serangkaian tindakan yang didesain untuk membantu bisnis mencapai tujuan menggunakan medium internet (online). Dalam hal ini UMKM di Kelurahan Gebang Kecamatan Masaran Kabupaten Sragen berupaya mencoba untuk menerapkan pemasaran melalui digital marketing. Jika dilihat secara kasat mata mungkin akan tampak mudah, bahkan sebagian berpikiran bahwa pemasaran digital sama dengan mempublikasi konten melalui media sosial, lalu mempercepat dengan iklan. Namun kenyataannya tidak sesederhana itu, perlu berbagai perencanaan untuk menghasilkan kampanye pemasaran yang efektif.

Penyusunan target dan strategi yang dilakukan dalam proses Pengabdian Kepada Masyarakat ini diawali dengan memulai strategi sendiri berupa rencana tindakan untuk mencapai tujuan yang diinginkan, dan disarankan tujuan tersebut harus dapat diukur dengan baik. Sebagai contoh yang telah dilakukan : melalui kampanye pemasaran digital yang dijalankan selama 2 bulan bagi UMKM di Kelurahan Gebang Kecamatan Masaran Kabupaten Sragen, dengan memanfaatkan tekhnologi yang telah dimiliki seperti handphone.

Namun strategi ini juga akan sangat bergantung dengan skala bisnis. Di tingkat startup, memiliki tujuan yang fokus dan sederhana sangat disarankan. Cara paling mudah ialah dengan membuat schedule plan berisi aktivitas apa saja yang akan dilakukan secara online. 
Hal yang harus dilakukan dalam menyusun strategi pemasaran bagi UMKM di Kelurahan Gebang Kecamatan Masaran Kabupaten Sragen adalah :

1. Pastikan target sudah didapat, sehingga ada angka yang bisa digunakan untuk mengukur hasil akhir.

2. Tentukan kerangka waktu pelaksanaan kegiatan pemasaran digital dan aktivitas yang akan dilakukan.

3. Identifikasi untuk mengetahui efektivitas pelaksanaan acara di waktu yang telah ditentukan tersebut. Misalnya jangan sampai melakukan promo hardselling untuk konversi penjualan ketika tanggal tua dll.

4. Tentukan kanal online yang akan digunakan untuk promosi.

\section{Memahami konsumen}

Memahami konsumen sangatlah penting dalam mengembangkan usaha bisnis, khusunya bagi UMKM di Kelurahan Gebang Kecamatan Masaran Kabupaten Sragen. Beberapa hal, yang perlu diketahui dalam memahami konsumen adalah melakukan segmentasi minat beli sebuah produk yang dilakukan oleh konsumen, serta memahami factor-faktor apa saja yang dapat mempengaruhi minat beli konsumen. Misalnya kualitas produk, tampilan produk, variasi harga, serta kualitas pelayanan yang telah diberikan oleh UMKM di Kelurahan Gebang Kecamatan Masaran Kabupaten Sragen.

Selain itu, UMKM di Kelurahan Gebang Kecamatan Masaran Kabupaten Sragen perlu memahami betul latar belakang konsumen, hal ini bisa dilihat dari pendapatan rata-rata penduduk, tingkat pendidikan, selera masyarakat sekitar. Dengan mengenali konsumen serta latar belakang konsumen, maka UMKM di Kelurahan Gebang Kecamatan Masaran Kabupaten Sragen akan mendapatkan cara yang efektif untuk menyampaikan promosi. Namun hal ini juga menjadi kendala, dikarenakan rata-rata UMKM di Kelurahan Gebang Kecamatan Masaran Kabupaten Sragen sudah memiliki usia diatas 40 tahun, sehingga perlu pendampingan bagi penerusnya, hal ini bisa dibantu oleh keluarga atau anak-anak mereka. Berdasarkan permasalahan tersebut, maka kegiatan Pengabdian Kepada Masyarakat ini berupaya melakukan pendampingan agar kegiatan bisnis dapat didampingi oleh kaum milinieal yang dapat memahami perkembangan tekhnologi dan selera konsumen saat ini.

\section{Memahami Brand yang Diusung}

Hal yang paling diperhatikan oleh pelaku bisnis adalah sebuah merek yang telah diciptakannya. Seperti penelitian yang dilakukan oleh Kurniawan, Arifin dan Fanani, (2018) menunjukkan bahwa citra merek berpengaruh signifikan terhadap keputusan pembelian. Berdasarkan hal terebut, proses Pengabdian Kepada Masyarakat ini berupaya menyampaikan kepada UMKM di Kelurahan Gebang Kecamatan Masaran Kabupaten Sragen bahwa penciptaan merek yang menarik itu adalah penting. Hal yang dapat dilakukan adalah bagaimana nama merek yang kita pilih dengan mudah dapat diingat oleh seluruh konsumen, dan bagaimana upaya yang dilakukan agar konsumen tidak berpindah kepada merek lain. Salah satu 
strategi yang diterapkan dalam proses Pengabdian Kepada Masyarakat ini adalah dengan menciptakan nama merek yang singkat, unik dan mudah diingat.

\section{Menyiasati Kompetisi Bisnis}

Dalam masa modern saat ini, kita selaku pelaku bisnis perlu berfikir lebih keras bagaimana tindakan yang dapat dilakukan untuk menyiasati kompetisi bisni. UMKM di Kelurahan Gebang Kecamatan Masaran Kabupaten Sragen disarankan dapat melakukan hal-hal sebagai berikut:

1. Amati dan pelajari pesaing usaha dengan mengamati perilaku pesaing atau kompetitor yang menjual produk yang sama, sehingga UMKM di Kelurahan Gebang Kecamatan Masaran Kabupaten Sragen perlu menciptakan inovasi produk yang unik dan menarik dibandingkan kompetitornya.

2. Pahami karakteristik usaha anda, memahami posisi usaha khususnya UMKM di Kelurahan Gebang Kecamatan Masaran Kabupaten Sragen adalah sangat penting, agar kita bisa lebih fokus dalam menjalankan usaha bisnis.

3. Amati,tiru dan perbarui, slogan ini bisa diterapkan bagi UMKM di Kelurahan Gebang Kecamatan Masaran Kabupaten Sragen agar mampu menciptakan inovasi-inovasi produk baru.

4. Cari mitra usaha, ini merupakan hal yang penting dengan kita mencari mitra usaha kita bisa saling bekerjasama dalam menjual produk.

5. Beri potongan harga dan diskon, ini adalah salah satu bentuk promosi agar dapat menarik konsumen untuk membeli sebuah produk.

6. Keramahan dalam komunikasi terhadap konsumen.

7. Jujur

\section{Mengukur Capaian}

Dengan dilaksanakan kegiatan Pengabdian Kepada Masyarakat ini diharapkan dapat meningkatkan kemampuan dan ketrampilan UMKM i Kelurahan Gebang Kecamatan Masaran Kabupaten Sragen dalam meningkatkan usahanya dan mampu memanfaatkan kemajuan tekhnologi yang berkembang saat ini. Tingkat pengukuran capaian kegiatan Pengabdian Kepada Masyarakat ini adalah sebagai berikut:

\begin{tabular}{|c|c|c|c|c|c|}
\hline \multirow[t]{2}{*}{ No } & \multirow[t]{2}{*}{ Sasaran } & \multicolumn{4}{|c|}{ Indikator Capaian Utama } \\
\hline & & Uraian & Target & Realisasi & $\%$ \\
\hline 1 & $\begin{array}{l}\text { Mengatasi } \\
\text { permasalahan } \\
\text { yang dihadapi } \\
\text { oleh UMKM } \\
\text { tentang proses } \\
\text { pemasaran } \\
\text { produk dengan } \\
\text { efektif dan } \\
\text { efisien }\end{array}$ & $\begin{array}{lr}\text { Menganalisa } & \\
\text { proses } & \\
\text { pemasaran } & \text { yang } \\
\text { selama } & \text { ini } \\
\text { dilakukan } & \text { oleh } \\
\text { UMKM } & \end{array}$ & $\begin{array}{l}\text { Mencipatkan } \\
\text { strategi } \\
\text { pemasaran } \\
\text { yang tepat }\end{array}$ & $\begin{array}{l}\text { Mampu } \\
\text { mencipatkan } \\
\text { strategi } \\
\text { pemasaran } \\
\text { yang baik }\end{array}$ & $80 \%$ \\
\hline
\end{tabular}




\begin{tabular}{|c|c|c|c|c|c|}
\hline 2 & $\begin{array}{l}\text { Memberikan } \\
\text { gambaran } \\
\text { kepada UMKM } \\
\text { apa yang } \\
\text { dimasud } \\
\text { dengan media } \\
\text { sosial }\end{array}$ & $\begin{array}{l}\text { Memberikan } \\
\text { sosialisasi } \\
\text { dengan metode } \\
\text { ceramah dan } \\
\text { presentasi } \\
\text { tentang media } \\
\text { sosial }\end{array}$ & $\begin{array}{l}\text { UMKM mampu } \\
\text { memahami } \\
\text { apa itu } \\
\text { pentingnya } \\
\text { media social } \\
\text { dalam proses } \\
\text { pemasaran }\end{array}$ & $\begin{array}{l}\text { Sebagian } \\
\text { UMKM dapat } \\
\text { memahami } \\
\text { pentingnya } \\
\text { media social } \\
\text { dalam } \\
\text { proses } \\
\text { pemasaran }\end{array}$ & $75 \%$ \\
\hline 3 & $\begin{array}{l}\text { Memberikan } \\
\text { penjelasan } \\
\text { tentang } \\
\text { manfaat } \\
\text { pemasaran } \\
\text { produk } \\
\text { menggunakan } \\
\text { media sosial }\end{array}$ & $\begin{array}{l}\text { Melakukan } \\
\text { diskusi tanya } \\
\text { jawab tentang } \\
\text { gambaran } \\
\text { bagaimana cara } \\
\text { mengaplikasikan } \\
\text { media sosial }\end{array}$ & $\begin{array}{l}\text { UMKM dapat } \\
\text { menggunakan } \\
\text { media social } \\
\text { dan sudah } \\
\text { mendaftar } \\
\text { misalkan } \\
\text { facebook atau } \\
\text { instagram }\end{array}$ & $\begin{array}{l}\text { Sebagian } \\
\text { UMKM dapat } \\
\text { mendaftar } \\
\text { media social } \\
\text { facebook } \\
\text { atau } \\
\text { instagram }\end{array}$ & $75 \%$ \\
\hline 4 & $\begin{array}{l}\text { Mampu } \\
\text { menciptakan } \\
\text { startegi dalam } \\
\text { menyiasati } \\
\text { kompetisi } \\
\text { bisnis }\end{array}$ & $\begin{array}{l}\text { Memberikan } \\
\text { penjelasan } \\
\text { bagaimana cara } \\
\text { menyiasati } \\
\text { kompetisi bisnis }\end{array}$ & $\begin{array}{l}\text { UMKM dapat } \\
\text { menganalisa } \\
\text { dan } \\
\text { menciptakan } \\
\text { startegi dalam } \\
\text { menyiasati } \\
\text { kompetisi } \\
\text { bisnis }\end{array}$ & $\begin{array}{l}\text { UMKM } \\
\text { mampu } \\
\text { menganalisa } \\
\text { latar } \\
\text { belakang } \\
\text { konsumen } \\
\text { dan } \\
\text { menciptakan } \\
\text { startegi } \\
\text { dalam } \\
\text { menyiasati } \\
\text { kompetisi } \\
\text { bisnis }\end{array}$ & $80 \%$ \\
\hline
\end{tabular}

\section{KESIMPULAN}

Kesimpulan dalam pengabdian masyarakat ini adalah UMKM di Kelurahan Gebang Kecamatan Masaran Kabupaten Sragen mampu memanfaatkan media social dalam mengembangkan bisnisnya. UMKM di Kelurahan Gebang Kecamatan Masaran Kabupaten Sragen sudah memulai metode pemasaran dengan memanfaatkan tekhnologi terbaru, yaitu dengan memperhatikan tujuh konsep pemasran ampuh dengan metode digital, diantaranya adalah Search Engine Optimization (SEO), Search Engine Marketing (SEM), Pembuatan Konten, Mobile Marketing, Email Marketing, Affiliate Marketing, Pemasaran Media Sosial. Pengabdian masyarakat ini diharapkan dapat dilakukan secara kesinambungan, setelah melakukan pengabdian tentang pentingnya pemasaran digital bagi pengembangan bisnis khususnya di UMKM di Kelurahan Gebang Kecamatan Masaran Kabupaten Sragen. Diharapkan kegiatan kedepan adanya pendampingan tentang bagaimana memberikan merk produk atau HAKI 


\section{REFERENCES}

Febriyantoro, (2018). Pemanfaatan Digital Marketing Bagi Usaha Mikro, Kecil Dan Menengah Pada Era Masyarakat Ekonomi Asean. JMD: Jurnal Manajemen Dewantara Vol 1 No 2, Desember 2018 http://ejournal.stiedewantara.ac.id/index.php/JMD/issue/view/32

Kurniawan, Arifin dan Fanani, (2018). Pengaruh Citra Merek Terhadap Keputusan Pembelian (Survei kepada para siswa SMAN 15 Surabaya kelas XII yang menggunakan Laptop ber Merek ASUS). Jurnal Administrasi Bisnis (JAB)/Vol. 56 No. 1 Maret 2018/ administrasibisnis.studentjournal.ub.ac.id

Peta Kab. Sragen: www.google.kab.sragen.co.id (Diakses pada tanggal 18 April 2019)

Purwana, Rahmi dan Aditya, (2017). Pemanfaatan Digital Marketing Bagi Usaha Mikro, Kecil, Dan Menengah (UMKM) Di Kelurahan Malaka Sari, Duren Sawit. Jurnal Pemberdayaan Masyarakat Madani (JPMM) E-ISSN: 25804332 Vol. 1 No. 1 Juli 2017 DOI: doi.org/10.21009/JPMM.001.1.01

https://drife.co.id/blog/7-konsep-pemasaran-ampuh-di-era-digital/ diakses 04 Mei 2019

Wardhana. (2015). Strategi Digital Marketing dan Implikasinya Pada Keunggulan Bersaing UMKdi Indonesia. In Seminar Nasional Keuangan dan Bisnis IV (pp. 327-337). Universitas Pendidikan Indonesia. 